\title{
S ЧЕЛОВЕК И ГОСУДАРСТВО
}

Байматов П.Н.

\section{ГОСУДАРСТВЕННЫЕ ГАРАНТИИ ПРАВА ГРАЖДАН РОССИЙСКОЙ ФЕДЕРАЦИИ НА СОЦИАЛЬНОЕ ОБЕСПЕЧЕНИЕ: СУДЕБНАЯ ЗАЩИТА}

\begin{abstract}
Аннотация: В статье исследовано понятие государственных гарантий права граждан Российской Федерации на социальное обеспечение, их взаимосвязь с определением соииальности государства. Особое внимание уделено государственной гарантии - конституционному принципу правосудия. Проанализирована специфика судебной защиты права на социальное обеспечение с точки зрения экономического потенциала государства, наличия финансовых ресурсов. Предметом исследования настоящей статьи является вопрос реализации гарантий конституционного права граждан на социальное обеспечение в Российской Федерации, в том числе с точки зрения осуществления судебного контроля за их реализацией. Указанные вопросы исследуются с помощью логического и системного методов, анализа и синтеза, формально-юридического, сравнительно-правового и историко-сравнительного методов познания. В статье выдвигается и обосновывается тезис о том, что государственные гарантии конституционного права граждан на социальное обеспечение являются одним из основных индикаторов социальности государства. Построение сочиального государства посредством усиления, в том числе, государственных гарантий реализачии конституционного права на социальное обеспечение - стратегическая задача и государственного аппарата и гражданского общества в иелом.
\end{abstract}

Abstract: The article involves the study of state guarantees of a right of citizens of the Russian Federation for social guarantees, their interrelation with the definition of sociality of a state. Special attention is paid to the state guarantee: a constitutional principle of justice. The author analyzes specific features of judicial protection of a right to social guarantees from the standpoint of economic potential of the state, presence of financial resources. The object of study involves implementation of constitutional guarantees of the rights of people for social guarantees in the Russian federation, including the judicial control over their implementation. The said issues are studied with the help of logical and systemic methods, analysis and synthesis, formal legal, comparative legal and historical comparative methods of cognition. The article presents and supports the thesis that state guarantees of a constitutional right of citizens to social guarantees are among the main indicators of social character of the state. Formation of the social state via strengthening of state guarantees of implementation of constitutional right to social guarantee is a strategic goal for both the state apparatus and a civil society as a whole.

Ключевые слова: Конститучия, сочиильное государство, гарантии, правосудие, судебные органы, принципы, индикаторы, социальное обеспечение, санаторно-курортное лечение, компетениия.

Keywords: Constitution, social state, guarantees, justice, judicial bodies, principles, indicators, social guarantees, health resort treatment, competence.

соответствии со ст.7 Конституции Российской Федерации «Российская Федерация - социальное государство, политика которого направлена на создание условий, обеспечивающих достойную жизнь и свободное развитие человека»'. Статьей 39

\footnotetext{
${ }^{1}$ См.: Конституция Российской Федерации (принята всенародным голосованием 12.12.1993) (с учетом поправок, внесенных Законами РФ о поправках к Конституции РФ от
}

Конституции Российской Федерации каждому гарантируется социальное обеспечение по возрасту, в случае болезни, инвалидности, потери кормильца, для воспитания детей и в иных случаях, установленных законом.

В Российской Федерации признаются и гарантируются права и свободы человека и гражданина согласно

30.12.2008 № 6-ФКЗ, от 30.12.2008 № 7-ФКЗ). Собрание законодательства РФ., 26.01.2009. № 4. ст. 445. 
общепризнанным принципам и нормам международного права и в соответствии с Конституцией Российской Федерации (ст. 17 Конституции Российской Федерации).

В Международном пакте об экономических, социальных и культурных правах, ратифицированном Президиумом Верховного Совета СССР 18 сентября 1973 г., предусмотрено право каждого человека на социальное обеспечение, включая социальное страхование (ст. 9). В ст. 11 данного Пакта признается право каждого на достаточный жизненный уровень для него и его семьи, включающий достаточное питание, одежду и жилище, и на непрерывное улучшение условий жизни. Государства обязаны принимать надлежащие меры к обеспечению осуществления этого права.

Однако для того, чтобы право на социальное обеспечение могло быть надлежащим образом реализовано, необходимо наличие конкретных гарантий, обеспечивающих, в том числе, в случае нарушения этого права его эффективное восстановление. Право только тогда реализуется, когда ему соответствует чья-то обязанность его обеспечить. Конституционная обязанность соблюдать и защищать права и свободы человека и гражданина состоит в создании условий реализации и механизма защиты.

Гарантии прав и свобод человека и гражданина это система социально-экономических, политических, нравственных, юридических, организационных предпосылок, условий, средств и способов, создающих равные возможности личности для осуществления своих прав, свобод и интересов. ${ }^{2}$

Традиционно систему гарантий конституционных прав и свобод граждан классифицируют на две группы: общие и специальные правовые (юридические). К общим гарантиям относят: экономические, социальные, политические, идеологические гарантии под которыми понимают совокупность экономических, социальных, политических, идеологических факторов, создающих условия и предпосылки для их реализации на конкретном этапе развития общества и государства. Определяющими в системе общих гарантий являются экономические, поскольку именно они обеспечивают максимум удовлетворения возрастающих материальных и духовных потребностей личности. Экономическими гарантиями выступают, прежде всего, различные формы собственности, экономическая политика государства, состоящая в поддержке различных общественных слоев.

\footnotetext{
${ }^{2}$ См.: Мордовеи А.С. Социально-юридический механизм обеспечения прав человека и гражданина/ Под ред. Н.И. Матузова. - Саратов, 1996. - С.15.
}

Однако общие гарантии не могут самостоятельно обеспечивать реализацию прав и свобод человека и гражданина без специальной юридической поддержки. Именно эту роль выполняют юридические гарантии, к которым относятся принципы, нормы права, законодательно установленные средства, призванные обеспечивать осуществление и охрану субъективных прав и свобод и в итоге пользование индивидом, лежащими в их основе благами ${ }^{3}$. В зависимости от основания закрепления специальные гарантии конституционных прав подразделяются на конституционные и отраслевые. Конституцией Российской Федерации установлен достаточно широкий набор гарантий прав и соответствующих процедур. Само по себе закрепление в Конституции РФ прав и свобод, уже является гарантией. Так, ст. 39 Конституции Российской Федерации непосредственно упоминается о гарантиях: «Каждому гарантируется социальное обеспечение по возрасту, в случае болезни, инвалидности, потери кормильца, для воспитания детей и в иных случаях, установленных законом» ${ }^{4}$. Таким образом, использование термина «гарантия», предполагает существование в государстве различных институтов: организационных, правовых и иных, обеспечивающих реализацию прав гражданами.

Наличие конституционных гарантий позволяет резюмировать реальность провозглашенных норм, их субъективный, действующий характер, обеспеченность не только и не столько индивидуальными возможностями отдельного гражданина, сколько всем существующим строем. ${ }^{5}$ В системе конституционных гарантий можно выделить несколько групп.

Первую группу конституционных гарантий составляют общие принципы юридических гарантий, направленные на обеспечение незыблемости конституционного строя, соблюдения и реализации прав и свобод человека и гражданина: принцип верховенства права (ст.1 Конституции Российской Федерации), разделения властей (ст.10 Конституции Российской Федерации), приоритет прав человека (ст.18 Конституции Российской Федерации) и другие.

Отдельную группу конституционных гарантий составляет деятельность Президента Российской Федерации как гаранта Конституции РФ, осуществляемая путем использования законодательной

\footnotetext{
${ }^{3}$ См.: Комаров С.А., Ростовщиков И.В. Личность. Права и свободы. Политическая система. - Спб., 2002. - С.59.

${ }^{4}$ См.: Конституция Российской Федерации 1993 г. - «Собрание законодательства РФ», 14.04.2014, № 15, ст. 1691.

${ }^{5}$ См.: Боброва Н.А. Конституционный строй и конституционализм в России. - М.,2003. - С.12.
} 


\section{Право и политика 8 (176) • 2014}

инициативы, при издании указов и распоряжений (например: Указ Президента РФ от 07.05.2012 № 597 «О мероприятиях по реализации государственной социальной политики» ${ }^{6}$ ), направленных на защиту прав личности, решение общих проблем в рамках государства.

В рамках настоящей статьи хотелось бы более подробно остановиться на особой группе конституционных гарантий, которыми являются конституционные принципы правосудия. К указанному принципу относятся: право каждого человека защищать свои права и свободы всеми способами, не запрещенными законом (ч.2 ст.45 Конституции Российской Федерации); судебная защита прав и свобод личности (п.1 ст.46 Конституции Российской Федерации), право на квалифицированную юридическую помощь (ст.48 Конституции Российской Федерации) и другие. Конституционные принципы правосудия направлены на недопустимость произвола должностных лиц в отношении личности, в том числе при реализации права на социальное обеспечение.

Необходимость в собственно защите конституционного права на социальное обеспечение возникает при его нарушении в форме принятия неправомерных нормативных правовых актов, необоснованный отказ в признании за лицом права, неисполнение кем-либо юридической обязанности.

Статья 18 Конституции Российской Федерации определяет, что «права и свободы человека и гражданина являются непосредственно действующими. Они определяют смысл, содержание и применение законов, деятельность законодательной и исполнительной власти, местного самоуправления и обеспечиваются правосудием»7. Указанная статья является частью общего механизма защиты прав и свобод человека и гражданина совместно с положениями ст.15 - о высшей юридической силе Конституции Российской Федерации и ее прямом действии и ст.46 - о праве каждого на судебную защиту. ${ }^{8}$

По мнению В.М.Жуйкова, право на судебную защиту Конституция Российской Федерации закрепляет не в качестве самого себя, как другие права (право на жизнь, на личную неприкосновенность, на свободу

\footnotetext{
${ }^{6}$ См.: Указ Президента РФ от 07.05.2012 № 597 «О мероприятиях по реализации государственной социальной политики». - «Собрание законодательства РФ», 07.05.2012, № 19, ст. 2334.

${ }^{7}$ См.: Конституция Российской Федерации 1993 г. - «Собрание законодательства РФ», 14.04.2014, № 15, ст. 1691.

${ }^{8}$ См.: Конституция Российской Федерации. Проблемный комментарий./ Под ред. В.А. Четвернина. - М.,2002. - С.179.
}

передвижения и другие), а в качестве гарантии всех прав и свобод человека и гражданина9.

Особенность судебной защиты социальных прав заключается в том, что суды, рассматривая дела данной категории, должны учитывать, что правоотношения государства и гражданина, определенные Конституцией Российской Федерации, во многом не обеспечены не только правовыми механизмами, но и не подкреплены соответствующими финансовыми ресурсами. С одной стороны, государство должное отвечать по своим конституционным социально-экономическим обязательствам в сфере перераспределения благ, находится в ситуации, когда удовлетворение требований одних, приводит к ущемлению прав других. С другой стороны, нуждающиеся в защите нарушенных, гарантируемых Конституцией Российской Федерации, правах граждане относятся к социально-уязвимым слоям, для которых нарушение их социально-экономических прав подрывает достойное существование.

В связи с этим, необходимо отметить ключевую роль конституционного правосудия как конституционной гарантии реализации права на социальное обеспечение, которое в своей основе содержит принцип реализации социальной справедливости. Правосудие призвано играть существенную роль в создании равных условий в политической, экономической и социальнокультурной областях. Именно деятельность судебных органов по социальной защите граждан необходимо рассматривать в общем русле реализации конституционных принципов социального правового государства в новых условиях социально-экономического и политического развития России.

Социальная проблематика весьма заметна в деятельности Конституционного Суда и судебных органов Российской Федерации в целом. Социальные вопросы в той или иной мере получили отражение в многих постановлениях Конституционного Суда, в которых, в частности, интерпретировались конституционные положения, касающиеся: социального обеспечения; пенсионной системы; возмещения вреда, ущерба и расходов в связи с: 1) незаконными действиями государственных органов и должностных лиц, включая судебные решения; 2) техногенными катастрофами и экологическими бедствиями; 3) политическими репрессиями; права на жилище; права на образование; труда и статуса безработных ${ }^{10}$.

\footnotetext{
${ }^{9}$ См.: Жуйков В.М. Судебная защита прав граждан и юридических лиц. - М.,1997. - С.151-180.

${ }^{10}$ См.: Бондарь Н.С. Конституционный Суд Российской Федерации - гарант социальных прав граждан. «Право и власть», № 2, 2002.
} 
Рассматривая роль судебных органов в целом в реализации и развитии конституционной концепции социальной защиты граждан необходимо определиться, прежде всего, с пределами конституционного регулирования социальных отношений, а также с возможностями прямого применения конституционных норм о социальных правах граждан и, соответственно, о юридической силе корреспондирующих материально-финансовых обязательств государства перед гражданами в социальной сфере. Основной определяющей проблемой является вопрос о том, в какой мере и каким образом судебные органы должны учитывать при разрешении конкретных дел о конституционности норм социального законодательства материальнофинансовые возможности государства. Кроме того, проблемным является механизм реализации решений судов различных инстанций по социальным вопросам, решение которых имеет не только правовой, но, прежде всего, финансово-экономический характер.

При осуществлении судебного контроля необходимо учитывать различные аспекты нормативно-правовой основы деятельности судов Российской Федерации. Прежде всего, на наш взгляд имеют значение компетенционные конституционно-правовые институты социальной защиты граждан, обусловленные разграничением законодательной и исполнительной компетенции в социальной сфере на различных уровнях деятельности публичной власти по социальной защите граждан, что особенно важно для федеративного государства. Так ст. 72, п. «ж» Конституции РФ устанавливается, что «социальная защита, включая социальное обеспечение», находится «в совместном ведении Российской Федерации и субъектов Российской Федерации»"

В качестве примера влияния института разграничения полномочий между федеральным центром и субъектами Российской Федерации можно привести получающую широкое распространение судебную практику в части обеспечения лиц с ограниченными возможностями санаторно-курортным лечением. Так, в период с 2013 года частыми стали исковые заявления граждан к Департаменту социального развития Тюменской области (далее-Департамент) о предоставлении им ежегодного санаторно-курортного лечения. С 01.01.2011 на основании соглашения от 20.12.2010 № 76, заключенного между Министерством здравоохранения и социального развития Российской Федерации и Правительством Тюменской области (далее -

\footnotetext{
${ }^{11}$ См.: Бондарь Н.С. Конституционный Суд Российской Федерации - гарант социальных прав граждан. «Право и власть», № 2, 2002.
}

Соглашение), реализацию федеральных полномочий в части предоставления гражданам санаторно-курортного лечения осуществляет Департамент. До 2011 года реализацию данных полномочий в Тюменской области осуществляло Государственное учреждение - Тюменское региональное отделение Фонда социального страхования Российской Федерации. Порядок предоставления санаторно-курортного лечения отдельным категориям граждан, включенных в федеральный регистр лиц, имеющих право на получение государственной социальной помощи, определен Федеральным законом от 24.11.1995 № 181-Ф3 «О социальной защите инвалидов в Российской Федерации», постановлением Правительства Тюменской области от 30.12.2010 № 394-п «О порядке осуществления переданных федеральных полномочий по предоставлению мер социальной защиты инвалидам и отдельным категориям граждан из числа ветеранов, а также по оказанию государственной социальной помощи в виде социальных услуг по предоставлению при наличии медицинских показаний путевок на санаторно-курортное лечение и бесплатного проезда на междугороднем транспорте к месту лечения и обратно» (далее по тексту - постановление № 394-п). Согласно действующему законодательству, в том числе в соответствии с п. 4 постановления № 394-п, п. 1 ст. 5 Соглашения финансирование расходов на оказание государственной социальной помощи в виде социальных услуг по предоставлению при наличии медицинских показаний путевок на санаторно-курортное лечение осуществляется за счет ассигнований федерального бюджета, передаваемых бюджету Тюменской области в форме субвенций. Правила предоставления и методика распределения субвенций, предоставляемых из федерального бюджета бюджетам субъектов Российской Федерации на осуществление переданных полномочий Российской Федерации по оказанию отдельным категориям граждан государственной социальной помощи в части предоставления при наличии медицинских показаний путевок на санаторно-курортное лечение, а также бесплатного проезда на междугородном транспорте к месту лечения и обратно утверждены постановлением Правительства Российской Федерации от 30.12.2009 № 1118. Объем финансовых средств, предусмотренных в федеральном бюджете бюджету субъектов Российской Федерации на осуществление в 2014 году переданных полномочий Российской Федерации по оказанию отдельным категориям граждан государственной социальной помощи в части предоставления при наличии медицинских показаний 


\section{Право и политика 8 (176) • 2014}

путевок на санаторно-курортное лечение, а также бесплатного проезда на междугородном транспорте к месту лечения и обратно, определен распоряжением Правительства РФ от 03.02.2014 № 127-р. Согласно п. 11, 27 Положением о порядке предоставления санаторно-курортного лечения отдельным категориям граждан, включенных в Федеральный регистр лиц, имеющих право на получение государственной социальной помощи, утвержденным постановлением № 394-П, обеспечение граждан санаторно-курортным лечением осуществляется Департаментом в хронологической последовательности по дате подачи заявления в пределах средств, поступивших из федерального бюджета в виде субвенций в бюджет Тюменской области. Приказом Минтруда России от 11.09.2013 № 459н «О нормативах финансовых затрат в месяц на одного гражданина, получающего государственную социальную помощь в виде социальной услуги по санаторно-курортному лечению, а также по предоставлению проезда на междугородном транспорте к месту лечения и обратно» установлен норматив финансовых затрат в месяц на одного гражданина по санаторно-курортному лечению в размере 103,75 руб. на 2014 год. Федеральным законом от 17.07.1999 № 178-Ф3 «О государственной социальной помощи» не установлены гарантии ежегодного, приоритетного либо внеочередного обеспечения санаторнокурортным лечением граждан, имеющих право на государственную социальную помощь. В Тюменской области проживает 57 тысяч получателей набора социальных услуг, имеющих право на санаторно-курортное лечение, бесплатный проезд на междугородном транспорте к месту лечения и обратно, из них около 15 тысяч человек (или 26\%) по медицинским показаниям, нуждаются в санаторно-курортном лечении. Оплата набора социальных услуг гражданами производится за счет части средств, осуществляемой ими ежемесячной денежной выплаты (ЕДВ). Механизм предоставления набора социальных услуг основан на принципе солидарного участия в нем всех соответствующих категорий граждан, вносящих в него часть ЕДВ, при условии, что услуги предоставляются незначительной части нуждающихся в них групп населения. Поэтому объем средств, предназначенный на финансовое обеспечение санаторно-курортного лечения, напрямую зависит от волеизъявления граждан на получение набора социальных услуг или отдельной социальной услуги. Между тем, с каждым годом растет число получателей ЕДВ, отказавшихся от получения набора социальных услуг, следовательно, уменьшается объем средств, передаваемых Тюменской области для обеспечения граждан льготных категорий санаторнокурортным лечением. В то же время граждане, не отказавшиеся от набора социальных услуг, получают услуги на суммы, в несколько раз превышающие средства, которые ими вносятся в виде части ЕДВ. Так, внося за санаторно-курортное лечение ежемесячно в 2013 году по 99,25 руб. (1191 рубль в год), гражданин фактически претендует на предоставление санаторно-курортной путевки стоимостью не менее 17 тыс. рублей. Исходя из изложенного, путевки на санаторно-курортное лечение предоставляются с учетом даты подачи заявления в соответствии с медицинскими показаниями и по мере обеспечения граждан льготных категорий с аналогичным профилем лечения, подавших заявление о предоставлении путевки ранее.

Так, в 2011 году органы социальной защиты населения обеспечивали граждан, нуждающихся в санаторно-курортном лечении, но не обеспеченных Государственным учреждением - Тюменским региональным отделением Фонда социального страхования Российской Федерации (заявки 20082010 гг. - 4,5 тыс. чел.). В 2012 году путевками обеспечивались граждане, подавшие заявления на санаторно-курортное лечение в 2011 году. В 2013 году обеспечивались граждане по заявлениям 2011 года, 1 квартала 2012 года.

Информация о дефиците денежных средств федерального бюджета, передаваемых бюджету Тюменской области в форме субвенций на указанные цели, постоянно доводится Департаментом до Министерства труда и социальной защиты населения Российской Федерации. Суды, удовлетворяя требования истцов о предоставлении санаторно-курортного лечения исходят из того, что:

1) периодом предоставления социальных услуг является календарный год;

2) истцу не может быть отказано в предоставлении государственной социальной помощи в виде обеспечения санаторно-курортной путевкой связи с недостаточным финансированием из федерального бюджета, поскольку Российская Федерация приняла на себя обязанность по возмещению данных расходов;

3) Федеральный закон от 17.07.99 №178-Ф3 «О государственной социальной помощи» не ставит право на получение путевки в зависимость от наличия либо отсутствия иных лиц, имеющих право на получение указанного вида социальной поддержки, а так же не содержит указание на предоставление путевки в порядке очередности для лиц равной категории. 
Таким образом, суды обязывают органы государственной власти субъекта предоставить гражданам санаторно-курортное лечение. Налицо необходимость изменения механизма предоставления указанной меры социальной поддержки, либо ее монетизация, либо предоставление необходимых медицинских услуг в амбулаторных условиях.

Изложенный пример, разумеется, не может передать всей полноты картины по защите прав граждан судебными органами. Вместе с тем, он в достаточной мере доказывает вывод о том, что рассмотрение указанной категории дел является одним из приоритетных направлений деятельности судов Российской Федерации. В этой сфере они достигают значительных, общественно значимых результатов, являясь существенным фактором социальной стабильности российских регионов, в деле утверждения конституционного принципа социального государства, защиты социальных прав граждан. Работа в данном направлении является одновременно их вкладом в укрепление конституционной законности, поскольку, как справедливо отмечается в правовых исследованиях, «концепция социального государства - один из современных постулатов конституционной законности» ${ }^{12}$.

В современном понимании социальные права находятся в одном ряду с иными основными правами и свободами человека и гражданина - личными и политическими. Это делает их конституционно равноценными и предполагает одинаковую правовую защиту, в том числе в рамках правосудия. Вместе с тем они обеспечиваются в той мере, в какой это требуется для поддержания социального мира и не ведет к чрезмерному ограничению классических личных и политических прав и свобод; реализация социальных прав нацелена не просто на создание достойного существования, а на то, чтобы помочь все большему числу людей включиться в отношения формального равенства (свободного эквивалентного обмена) и преуспеть в них, чем, кстати, преодолевается одно из основных противоречий - между требованиями социальной справедливости и правового равенства. В этом отношении правосудие как конституционная гарантия реализации права граждан на социальное обеспечение является, на взгляд автора, одним из необходимых индикаторов социальности государства, перечень которых весьма подробно и детально изложен в статье Чиркина В.Е. «Конституция и социальное государ-

${ }^{12}$ См.: Хабриева Т.Я. Конституция как основа законности в Российской Федерации // Журнал российского права. 2009. № 3. ство: юридические и фактические индикаторы» ${ }^{13}$. По мнению автора настоящей статьи, перечисленные уважаемым профессором, доктором юридических наук, Чиркин Вениамином Евгеньевичем, индикаторы , возможно дополнить таким показателем как отправление правосудия в сфере защиты социальных прав.

\section{Библиография:}

1. Боброва Н.А. Конституционный строй и конституционализм в России. - М.,2003. - С.12.

2. Бондарь Н.С. Конституционный Суд Российской Федерации-гарант социальных прав граждан. «Право и власть», № 2, 2002.

3. Жуйков В.М. Судебная защита прав граждан и юридических лиц. - М.,1997. - С.151-180.

4. Комаров С.А., Ростовщиков И.В. Личность. Права и свободы. Политическая система. - Спб., 2002. - С.59.

5. Конституция Российской Федерации (принята всенародным голосованием 12.12.1993) (с учетом поправок, внесенных Законами РФ о поправках к Конституции РФ от 30.12.2008 № 6-ФКЗ, от 30.12.2008 № 7-ФКЗ). Собрание законодательства РФ., 26.01.2009. № 4. ст. 445.

6. Конституция Российской Федерации. Проблемный комментарий./ Под ред. В.А. Четвернина. - М., 2002. - C.179.

7. Мордовец А.С. Социально-юридический механизм обеспечения прав человека и гражданина/ Под ред. Н.И. Матузова. - Саратов, 1996. - С.15.

8. Указ Президента РФ от 07.05.2012 № 597 «О мероприятиях по реализации государственной социальной политики». - «Собрание законодательства РФ», 07.05.2012, № 19, ст. 2334.

9. Чиркин В.Е. Конституция и социальное государство: юридические и фактические индикаторы «Журнал российского права», 2008, №12.

10. Хабриева Т.Я. Конституция как основа законности в Российской Федерации // Журнал российского права. 2009. № 3.

11. Владимирова Т.В.. Информационная безопасность: социальные практики и структуры // Национальная безопасность / nota bene. - 2014. - № 3. - C. 104-107. DOI: $10.7256 / 2073-8560.2014 .3 .11511$

12. Ханнанов Р.А. Новая парадигма труда:теоретикоправовое обеспечение // NB: Экономика, тренды

\footnotetext{
${ }^{13}$ См.: Чиркин B.E. Конституция и социальное государство: юридические и фактические индикаторы «Журнал российского права», 2008, №12.
} 


\section{Право и политика $8(176) \cdot 2014$}

и управление. - 2013. - № 4. - C.93-157. DOI: 10.7256/2306-4595.2013.4.4175. URL: http://enotabene.ru/etc/article_4175.html

13. Адмиралова И.А.. Общественный порядок и права граждан // Полицейская деятельность. - 2014. - № 3. - C. 104-107. DOI: 10.7256/2222-1964.2014.3.12362

14. Човган И.В. Анализ влияния процесса глобализации на обеспечение национальной безопасности государства в сфере высшего образования // NB: Вопросы права и политики. - 2013. - № 5. - С.135149. DOI: 10.7256/2305-9699.2013.5.739. URL: http://enotabene.ru/lr/article_739.html

15. Алёшина М.В.. Сплоченность общества как новый тренд социальной политики: социологический анализ // Политика и Общество. - 2014. - № 5 . C. 104-107. DOI: 10.7256/1812-8696.2014.5.9512

16. Кананыкина Е.С. Нормативно-правовое обеспечение обучения лиц с ограниченными возможностями в системах образования Франции и США // NB: Проблемы общества и политики. - 2013. - № 3. - C.74-103. DOI: 10.7256/23060158.2013.3.455. URL: http://e-notabene.ru/pr/ article_455.html

17. Киреева Н.В.. Социальное интегрирование и интегрированный социум: интеграция как процесс и структура // Философия и культура. - 2014. № 5. - С. 104-107. DOI: 10.7256/1999-2793.2014.5.10931

18. Бродская И.М.. Эволюция форм социальной помощи с позиций семиотического подхода (на примере России) // Политика и Общество. - 2014. - № 4. C. 104-107. DOI: 10.7256/1812-8696.2014.4.11917

19. Трофимова И.Н.. Территориальные сообщества и социальное развитие молодежи: уровни, модели и структуры влияния // Политика и Общество. - 2014. - № 3. - C. 104-107. DOI: 10.7256/18128696.2014.3.11626

20. Исмаилов Н.О.. Справедливое общество как проект будущего в философии А. М. Ковалёва // Политика и Общество. - 2014. - № 3. - С. 104-107. DOI: 10.7256/1812-8696.2014.3.1143

21. С. Н. Бризецкий Институт гарантий прав инвалидов в конституционно-правовой системе Российской Федерации // Политика и Общество. - 2011. - 11. - C. $128-135$.

22. Лычагин А.И., Кузьмина Ю.А. Современные конституционные гарантии защиты прав личности в Российской Федерации и международные нормы в области защиты прав человека // Политика и Общество. - 2013. - 7. - С. 870 - 876. DOI: 10.7256/1812-8696.2013.7.2516.
23. О. Н. Доронина Судебная защита основных прав и свобод человека и гражданина в системе государственной защиты прав и свобод человека и гражданина в России и постсоциалистических государствах Европы // Политика и Общество. 2011. - 7. - C. $99-108$.

\section{References (transliteration):}

1. Bobrova N.A. Konstitutsionnyi stroi i konstitutsionalizm v Rossii. - M., 2003. - S.12.

2. Bondar' N.S. Konstitutsionnyi Sud Rossiiskoi Federatsii-garant sotsial'nykh prav grazhdan. «Pravo i vlast'», № 2, 2002.

3. Zhuikov V.M. Sudebnaya zashchita prav grazhdan i yuridicheskikh lits. - M., 1997. - S.151-180.

4. Komarov S.A., Rostovshchikov I.V. Lichnost'. Prava i svobody. Politicheskaya sistema. - Spb., 2002. - S.59.

5. Mordovets A.S. Sotsial'no-yuridicheskii mekhanizm obespecheniya prav cheloveka i grazhdanina/ Pod red. N.I. Matuzova. - Saratov, 1996. - S.15.

6. Chirkin V.E. Konstitutsiya i sotsial'noe gosudarstvo: yuridicheskie i fakticheskie indikatory «Zhurnal rossiiskogo prava», 2008, №12.

7. Khabrieva T.Ya. Konstitutsiya kak osnova zakonnosti v Rossiiskoi Federatsii // Zhurnal rossiiskogo prava. 2009. № 3.

8. Vladimirova T.V.. Informatsionnaya bezopasnost': sotsial'nye praktiki i struktury // Natsional'naya bezopasnost' / nota bene. - 2014. - № 3. - S. 104-107. DOI: 10.7256/2073-8560.2014.3.11511

9. Khannanov R.A. Novaya paradigma truda:teoretikopravovoe obespechenie // NB: Ekonomika, trendy i upravlenie. - 2013. - № 4. - S.93-157. DOI: 10.7256/23064595.2013.4.4175. URL: http://e-notabene.ru/etc/ article_4175.html

10. Admiralova I.A.. Obshchestvennyi poryadok i prava grazhdan // Politseiskaya deyatel'nost'. - 2014. - № 3. - S. 104-107. DOI: 10.7256/2222-1964.2014.3.12362

11. Chovgan I.V. Analiz vliyaniya protsessa globalizatsii na obespechenie natsional'noi bezopasnosti gosudarstva v sfere vysshego obrazovaniya // NB: Voprosy prava i politiki. - 2013. - № 5. - S.135-149. DOI: 10.7256/2305-9699.2013.5.739. URL: http://e-notabene. $\mathrm{ru} / \mathrm{lr} /$ article_739.html

12. Aleshina M.V.. Splochennost' obshchestva kak novyi trend sotsial'noi politiki: sotsiologicheskii analiz // Politika i Obshchestvo. - 2014. - № 5. - S. 104-107. DOI: $10.7256 / 1812-8696.2014 .5 .9512$ 
DOI: $10.7256 / 1811-9018.2014 .8 .12557$

При цитировании этой статьи сноска на dоі обязательна

Человек и государство

13. Kananykina E.S. Normativno-pravovoe obespechenie obucheniya lits c ogranichennymi vozmozhnostyami v sistemakh obrazovaniya Frantsii i SShA // NB: Problemy obshchestva i politiki. - 2013. - № 3. S.74-103. DOI: 10.7256/2306-0158.2013.3.455. URL: http://e-notabene.ru/pr/article_455.html

14. Kireeva N.V.. Sotsial'noe integrirovanie i integrirovannyi sotsium: integratsiya kak protsess i struktura // Filosofiya i kul'tura. - 2014. - № 5. - S. 104-107. DOI: 10.7256/1999-2793.2014.5.10931

15. Brodskaya I.M.. Evolyutsiya form sotsial'noi pomoshchi s pozitsii semioticheskogo podkhoda (na primere Rossii) // Politika i Obshchestvo. - 2014. - № 4. - S. 104-107. DOI: 10.7256/1812-8696.2014.4.11917

16. Trofimova I.N.. Territorial'nye soobshchestva i sotsial'noe razvitie molodezhi: urovni, modeli i struktury vliyaniya // Politika i Obshchestvo. - 2014. - № 3. - S. 104-107. DOI: 10.7256/1812-8696.2014.3.11626
17. Ismailov N.O.. Spravedlivoe obshchestvo kak proekt budushchego v filosofii A. M. Kovaleva // Politika i Obshchestvo. - 2014. - № 3. - S. 104-107. DOI: 10.7256/1812-8696.2014.3.1143

18. S. N. Brizetskii Institut garantii prav invalidov v konstitutsionno-pravovoi sisteme Rossiiskoi Federatsii // Politika i Obshchestvo. - 2011. - 11. - C. 128 - 135.

19. Lychagin A.I., Kuz'mina Yu.A. Sovremennye konstitutsionnye garantii zashchity prav lichnosti v Rossiiskoi Federatsii i mezhdunarodnye normy v oblasti zashchity prav cheloveka // Politika i Obshchestvo. - 2013. - 7 . - C. 870 - 876. DOI: 10.7256/1812-8696.2013.7.2516.

20. O. N. Doronina Sudebnaya zashchita osnovnykh prav i svobod cheloveka i grazhdanina $\mathrm{v}$ sisteme gosudarstvennoi zashchity prav i svobod cheloveka $i$ grazhdanina v Rossii i postsotsialisticheskikh gosudarstvakh Evropy // Politika i Obshchestvo. - 2011. - 7. - C. $99-108$. 